\title{
Apparatus X: Designing an Architecture for Civic Engagement
}

\section{AARON WERTMAN}

Pennsylvania State University

\section{MARCUS SHAFFER}

Pennsylvania State University

\section{JAMES KALSBEEK}

Pennsylvania State University
Typically defined as one who uses design as tools for political change, immediate response, and/or design-as-reaction, an activist architect can be more simply described as one who takes architectural practice with him/her, commits to a community, and engages with that community's building needs - as rejuvenation, or in more extreme cases, as response to disaster caused by war, weather, or economics. These informal situations (outside of the realm of normal procedure) call for Activist Architect to be nimble, resourceful, and responsive (qualities of activism), but how does formal and informal knowledge, professional training, and experience - embodied and transmitted through the architecture - get to communities in need in order to effect change?

Perhaps the answer to this question requires design. Apparatus $\mathrm{X}$ is a mobile design/construction studio developed to facilitate the essentials of architectural activism: responsiveness, tools/transmission, and the establishment of relationships where knowledge sharing, design and engagement occur.

\section{ENABLING CIVING ENGAGEMENT AND ARCHITECTURAL ACTIVISM}

The profession of architecture has a long history of advocating for the architect's participation in civil discourse, public interest architecture, and activism. The architect has the ability to contribute meaningfully to complex situations of the modern world regarding housing disparity, changing building paradigms, and limited resource availability through design thinking and creative works, but such activity is often considered marginal within the field of architecture. As design-build and community outreach have expanded the profession toward the realm of complexity, 'fuzzy logic', informal settlements, and new types of urban morphologies ${ }^{1}$ architects have drifted away from the office environment into academia, the Fine Arts, woodworking, fabrication, and other crafts as means of realizing the full value of their design thinking beyond the boundaries somewhat arbitrarily set by the profession of architecture.

While architecture acts as a profession for community engagement, within the profession there is actually a limited amount of support; politically, financially, and structurally, for the work of the activist architect. In response to the call for support of a marginalized, but impactful practice of architectural design in areas of desperate need, an alternative 


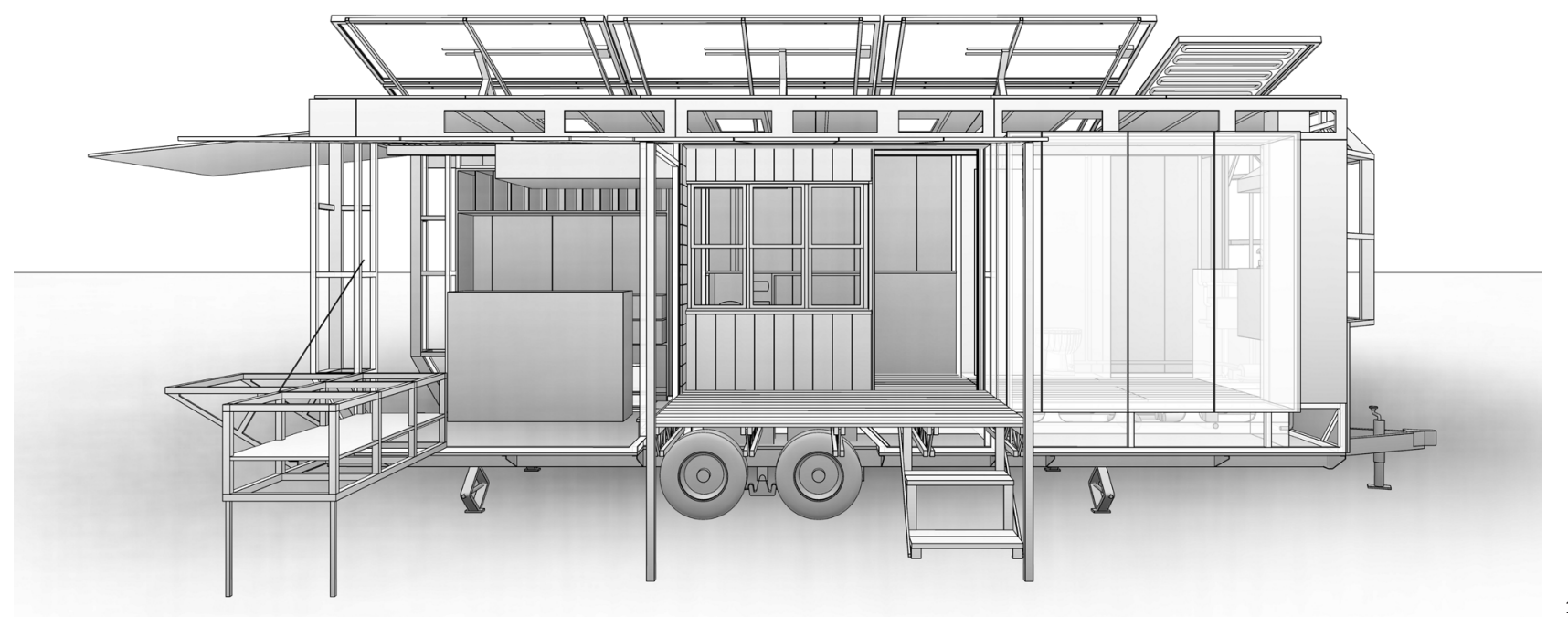

engagement strategy is proposed - an architectural activism that is tied to direct community engagement and reciprocal design, and proposes a multi-function tool/workshop/office designed specifically to activate the activist. Apparatus $X$, the design/build project, is an attempt to prepare an activist architecture for effective engagement outside the realm of normal architectural procedure.

Apparatus $X$ is a self-sufficient unit that acts as an adaptable tool trailer, mobile design studio, and micro living unit designed to take architectural activism to people who need help in rebuilding after conflict, natural disasters, or catastrophic failures in infrastructures that support housing (such as financial, or governmental). It is a project that is not just about design-build, but social engagement and action.

\section{THE DISCOURSE OF ARCHITECTURAL ACTIVISM FROM WITHIN THE PROFESSION}

In the existing discourse of architectural activism, there are a series of definitions and terms that help to identify the roles, duties, and interests of a civically engaged architect - referred to as the activist architect.

As evidenced in the collection of work in their book Expanding Architecture: Design as Activism, Bryan Bell and Katie Wakeford identify the public interest architect as one who makes a career as an architect serving those who need the most help, is fully dedicated to public service work while still making a living, and is engaged in their communities. The public interest architect is also entrepreneurial, and applies design skills and architectural ideas to problems previously considered the exclusive domain of public health officials, environmentalists, and community activists. ${ }^{2}$

In 2008, the AIA Board of Directors passed the Citizen Architect Resolution. This document aimed to establish support and advocacy for civically engaged architects that "serve" their community. Through this document, the AIA commends engagement with local, state, and federal issues, gaining appointment to boards and commissions, and those who advocate for higher living standards, the creation of livable, sustainable communities, and the greater public good. They also state in the document that the AIA believes that these members should be actively supported at all levels of service. ${ }^{3}$

The Development Activist, according to Sumita Sinha, works in a world defined by rapid change and scarce resources, responding to a complex and chaotic world while making meaning of it and proposing solutions. In her book Architecture for Scarce Resources and
Figure 1: Apparatus X, Expanded side view, (Rendering: Aaron Wertman) 


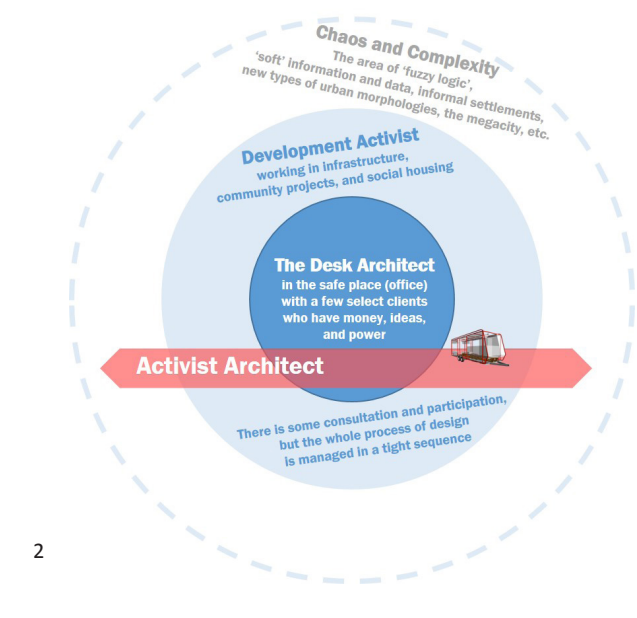

Rapid Change, Sinha describes an architectural activism that requires development skills, fundraising abilities, management skills, reciprocal design practices, itinerant practice, hyper-resourcefulness, self-motivation, and self-reliance.

Roberta M. Feldman defines Activist Practice as "The act of architects leaving the office, engaging the community, and seeking a need for design in that community, rather than passively waiting for clients to come to them."4 This notion can be explored through Sinha's concentric circles of design analogy (Fig. 2). The desk architect traditionally practices in the innermost circle - the safe place of "the office" with a few wealthy clients. The next circle contains development activists working in areas such as infrastructure, community projects or social housing and interacting with housing associations and local government bodies, but projects are managed in a tight sequence. The outermost fringe is the larger world of chaos and complexity - the area of 'fuzzy logic', of 'soft' information and data, of informal settlements, new types of urban morphologies such as the code-resistant megacity, of sustainable development, culture, etc.

As the profession expands and evolves, architects continue to drift towards the fringe, but find financial and political challenges to implementing and sustaining effective engagement practices. Apparatus $X$ intends to allow the architect to flow freely across this boundaries while still providing an effective service.

ACTIVIST ARCHITECT FOREFATHERS - VOICES OUTSIDE THE BOUNDS OF THE PROFESSION In addition to the existing discourse from within the profession, there are a few "activist architect forefathers" that help to inform/influence the definition of architectural activism from outside the bounds of the profession.

Kim Jae-kwan decidedly introduces himself as an ex-architect to make clear his newly defined role and intentions. After conducting the 'Daily Architecture Office' program, in which architects opened their doors to the public to offer consulting and design dialog, Kim decided to use the skills, knowledge, and experience he developed in dealing with the design and construction process, to create a more meaningful, helpful, and intimate connection with homeowners by transitioning from the role of architect to home repair man and woodworker. With a more engaged social presence, sound architectural design and building skills, and the capacity to build informal and formal relationships to both the community and the profession, Kim's value, effectiveness, and happiness have all improved. ${ }^{5}$

Using the beauty of found materials, Martin Kaltwasser, along with his partner Folke Köbberling, create interactive pieces of architectural work in public spaces. These works generate interaction and community dialog while not explicitly prescribing their use. This activist architect has stepped away from traditional architectural practice to engage in a dialog of radical material reuse and positive social change through self-built architecture.

Samuel Mockbee turned to academia to develop an active and engaged approach to provide architecture to people in need in his own backyard of Hale County, Alabama. His response is driven by the moral obligation that Mockbee believes is inherent to the profession. Through the Rural Studio, Mockbee provided students with an immersive experience in a project scenario that amplifies the feeling of moral obligation and a spiritual nature of architecture. Mockbee placed an immense amount of responsibility on the shoulders of the students, prompting action, intuitive decision-making, and responsive design solution that are immediate and effective. The Rural Studio offers an environment of education through experience - a valuable and typically more effective strategy.

Figure 2: Concentric Circles of Design, (Diagram: aron Wertman)
CHARACTERISTICS AND INFLUENCES THAT SHAPE THE ACTIVIST ARCHITECT

Informed by the definitions and examples around the existing discourse, there are a series 
of characteristics and influences associated to Humanism that must also shape the attitude, thoughts, character, and skillset of the activist architect:

EXPERIENCE \& IMMERSION: Direct exposure vs. "Visits" (including digital exposure) Direct exposure and immersion in a community, in which one becomes a neighbor in that community, makes community problems and concerns your problems and concerns. It turns the architect's solutions (so often "delivered" from a removed position) into our solutions (as a community). This immersive and inclusive condition is not generated from site visits and client meetings (including community or "town hall" meetings).

COMPASSION, SYMPATHY, LOVE FOR FELLOW MAN: Extrinsic vs. Intrinsic motivation; Moral; Spiritual obligation; A return or emphasis on ethics tied to real work - Extrinsic motivations arise from outside of the individual and often involve rewards, while intrinsic motivations arise from within the individual and involve personal fulfillment, satisfaction, and happiness. As informed by the case studies, activist architects seem to blur the lines between the two, resulting in a hybrid motivation that involves the physical production of an architectural work and the happiness associated with it from both the community member and the architect.

These factors are human nature, and a social value that we teach by example. Despite religious and spiritual connections to these factors, they are more directly informed by experience and immersion (previously mentioned) with people and the development of relationships that draw these qualities out of all of us. It is dependent then on the individual to retain the value and in turn translate these feelings to action.

A CHANGE IN VALUES: Market forces (capitalistic) vs. People; Relationships; Community; AND the changing realm of architectural practices - 1 - Change in value system (from the eyes of the activist architect) - FROM: a perspective that emphasizes monetary value, serving a clientele, both individual and corporate, that has the wealth to pay for architectural services and specialized design TO: a perspective that values the quality of life and provision of basic needs particularly shelter, that all individuals, rich or poor deserve.

2 - Change in the value of the architect as a professional in the design and construction processes - Architect was once one of the four titles that actually defined the term "profession" with the other three being doctor, lawyer, and clergy. Even further back in history, the architect was the "master builder" literally defined as such: arkhi meaning "chief" and tekton meaning "builder, carpenter." Today, as cost efficiency and energy efficiency continue to rise as primary drivers for building design, the value of the architect has unfortunatley become more and more marginalized.

HOLISTIC THINKING: The big picture; The ability to step outside to see it - It can be argued that this notion is something all architects should be able to do. However, the ability to step into the community dialog/mind/framework, while offering a holistically-minded perspective - especially in the case of a community project where there are numerous stakeholders and various levels both horizontally and vertically - enables the activist architect to understand the areas/goals that can be most effectively impacted, as well as the stakeholders that are affected by (and can affect) each aspect of the big picture. This skill also illustrates the type of inclusive relationship that an activist architect has to his/her community.

ARCHITECTURAL EDUCATION: Formal (NAAB-centric) vs. Informal (experiential; volunteer) - In addition to the formal education provided by NAAB-centric university programs which develops valuable architectural and visual communication skills, participation in things like charities, church organizations, youth groups, and volunteerism provides immersive experiences, informal education, and helps to build intangible skills - commmunication, 


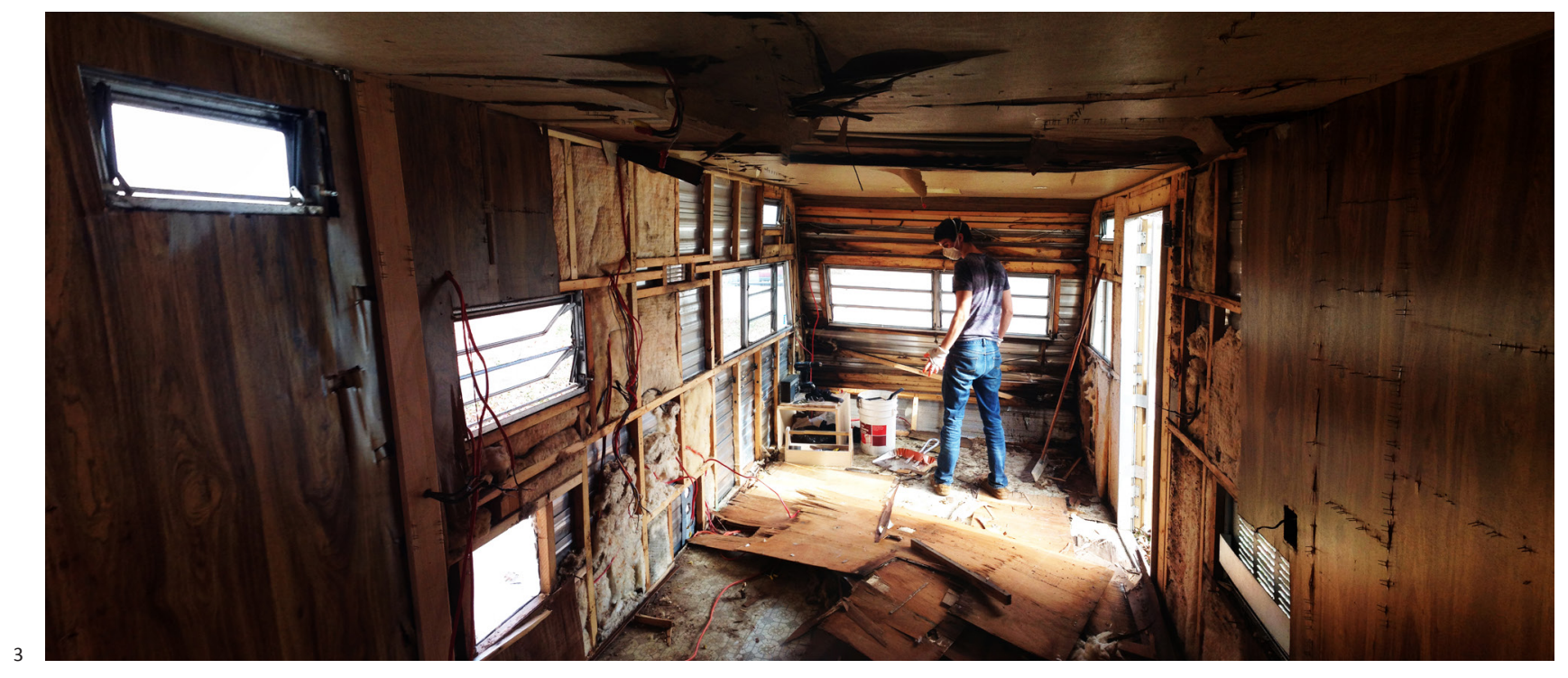

relationship-building, compassion, sympathy, understanding, holistic vision, progressive dialog, character growth. Despite similar informal notions that are presented and experienced through immersive design/build programs like Mockbee's Rural Studio, neither academic community engagement projects, nor alternative volunteer experiences provide a community driven framework where solutions are generated through reciprocal design dialog and a grassroots, community owned strategy for progress.

\section{ARCHITECTURAL ACTIVISM MANIFESTED IN APPARATUS $X$}

Informed by the existing discourse, exciting practices outside of the profession, and the essentials of communal work, we arrive at a definition of an activist architect that is:

- Itinerant

- Mobile

- Embedded

- Practices reciprocity in design

- Encourages self-progressive thought and action

- Possesses many comprehensive skills beyond design

- Responds nimbly to adverse conditions

- Is a community member, a neighbor, a friend

- Has the ability to cross the thresholds of the realms of the profession

- Offers compassion and understanding

- Practices sound judgment and professional etiquette

- Listens as well as speaks when called upon to do so, and

- Can holistically contribute to communities in need.

This idea manifests itself in Apparatus X conceptually, physically, and through the ethos of the project execution.

This project does not propose a structure/framework for professionals to drop what they're doing and embed in communities, but it does present a potential solution to the question: How does formal and informal knowledge, professional training, and experience get to communities in need in order to effect change? It creates a tool, and essential spaces, that ultimately form a manifestation of the activist architect, called Apparatus X.

Figure 3: nbuilding and Learning, (Photo: aron Wertman)

Through an embedded physical presence in the community, it makes the architect, and the profession of architecture, directly accessible to those who need architecture's 
skills, knowledge and sensibilities, rather than relegating community engagement to a marginal practice. With a prepared physical presence, the activist architect can engage in design activities and tasks WITH the community rather FOR the community. In this way, there is reciprocity in learning, designing, and building that provides local knowledge and direct feedback to the activist architect, creating an environment of effective design and engagement for the betterment of communities and individuals in need. Apparatus $X$ and the type of engagement it supports are not simply about participatory design, but rather responding to the needs of an individual on both a temporal and a metaphysical level. At the core of Apparatus $X$ lie the principles of education through experience, tooling and building as empowerment, and an attitude of self-progressive community activism.

Apparatus $X$ advocates an embedded presence in the community, grassroots community generated interventions/solutions (inside-out instead of outside-in), reciprocity in design dialog (it's never a project delivery scenario), collective knowledge (local knowledge and direct feedback), and empowerment through building/tooling.

For me, as a student of architecture and a person who has been involved in community re-building, Apparatus $X$ is a tool of anticipation - a tool designed for engagement; a tool prepared to address unknown factors that shape re-building efforts; a tool that creates an environment of effective design for the betterment of communities and individuals in need.

Composed of live space, work space, and flexible communal space, Apparatus $\mathrm{X}$ provides a forum for community voice and the exchange of design thinking. The project is physically described in three ways: Adaptable tool trailer, Mobile Design Studio, and Micro-living unit.

\section{ADAPTABLE TOOL TRAILER}

Tools harbor an embodied knowledge and memory. Tools are created as an extension of self to enable the completion of a task incapable of being competed by natural or human process/action alone. Since tools are typically governed by specificity of task - hammering, tightening a screw, nut, or bolt, sawing, prying cutting, etc. - dissociation of the tool with the task is nearly impossible. As a result, many tools prompt a natural interaction with the user, and thus inherently transmit knowledge and skill. Armed with a mastery of tools and the physical artifacts themselves, and activist architect can allow the tools to transmit knowledge with equal if not greater effectiveness than what the architect is able to articulate themselves.

Tools make an impossible task possible - provide strength. Tools are empowering - The tool alone cannot be productive, nor the hand alone be effective. The true strength lies in the marriage of the hand and the tool. Tools evolve. Apparatus $X$ is the evolution of a tool. If a tool is created as an extension of self to enable the completion of a task incapable of being completed by natural or human process/action alone, then Apparatus $\mathrm{X}$ is the extension of a community enabling building projects and design that responds to the needs of the community that have not/are not being effectively addressed. As something that is not just reserved for the architect, Apparatus $X$ is also the tool of the people, bringing the realm of architecture, including tools and design, to those who need it, and providing empowerment through building.

As an adaptable tool trailer, Apparatus $\mathrm{X}$ is capable of transforming an empty lot into a workspace. Building as empowerment is key to the intentions and success of Apparatus $X$. In order to build, a workspace, tools, and general means of construction are necessary. Since the variability of conditions of architectural activism sites will typically not be able to support a program of building/construction, it is required that Apparatus $\mathrm{X}$ is able to do so.

Through tooling, building, participatory design processes, or hands-on building and cleanup activities enabled by the interaction with Apparatus $\mathrm{X}$, community members actively 


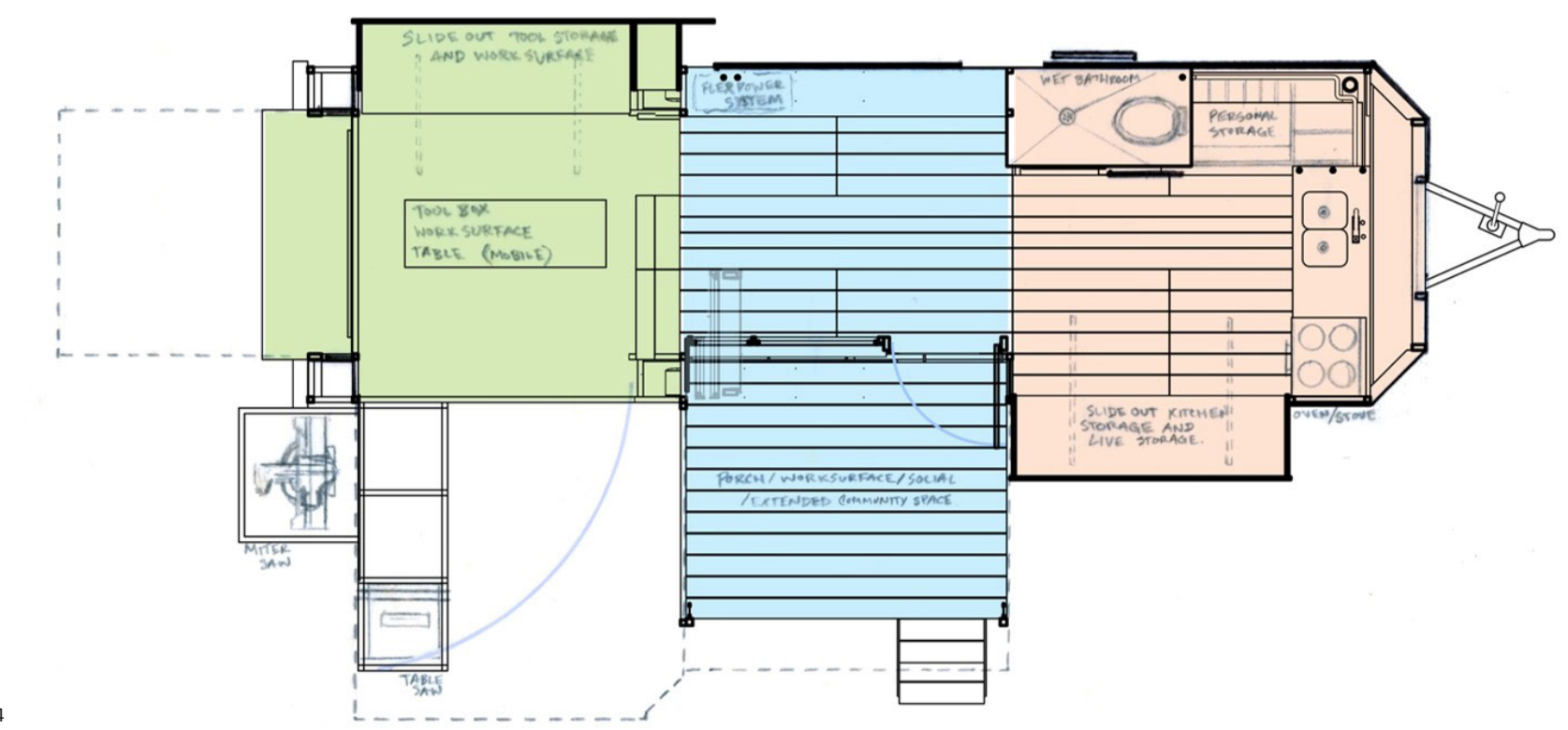

participate to make a difference in shaping their surrounding environment. As basic as this can be, participation acts as enabling activity renewing intangible aspects to community: pride, confidence, comfort, and care. In this sense, self-building holds two meanings: 1) the physical act of construction conducted by oneself, and 2) the intangible and internal fostering of confidence, pride, self-esteem, etc. within the character of an individual (similar to the activities that counseling service can offer).

\section{MOBILE [CO]DESIGN STUDIO}

With an open central module layout, Apparatus $X$ acts as a mobile design studio for both individual and community design, and aims to foster collective knowledge and provide a collaborative learning environment. In order to make the profession accessible, the activist architect leaves the office and embeds in a place. To do so, an itinerant but functioning space must be able to provide similar capabilities and tools to the office counterpart.

As an additional aspect of Apparatus $\mathrm{X}$ aiming to enable greater participation and provide increased access to design tools, a projector is used in conjunction with a chalkboard surface to display information or drawings. Considering that drawing acts as a means of universal communication, large drawing surfaces are key to promoting design dialog, conveying ideas, and providing an inclusive medium. Through the use of alternative media strategies - photographs, chalkboards, and projections - design can build and develop across a multiplicity of perspective and inputs creating in a way a palimpsest of design intention.

\section{MICRO-HOUSE}

Apparatus $X$, the micro-home unit, functions efficiently and illustrates a comfortable and efficient living environment for the inhabitant - an activist architect. If travel and embedding into a community are essential, the unit must be able to provide support for living anywhere and everywhere.

Figure 4: Expanded Spatial Layout of Apparatus $X$ - Plan view, (Drawing: aron Wertman)
The unit contains a small, enclosed wet bathroom including toilet and shower, a personal storage area for clothing and other items, a sink, stove, and oven operating on propane. 
The bed is mounted on rails overhead (enabling even weight distribution and variable spatial arrangement), the underside of which doubles as a lighting fixture. The table folds out from the heavy rolling toolbox, and a porch extends from the passenger side. While it can be argued that a porch is unnecessary to the overall concept of the design, it is actually an important design feature addressing sensitivity to place as well as conveying that this is something more than just a mobile tool trailer. The porch, along with the kitchen table, is a place of informal thought exchange (friendly/neighborly conversation); A place of trust built through relationships; A place of home and comfort.

\section{DESIGN/BUILD PROJECT EXECUTION OF APPARATUS $X$}

In the physical sense, Apparatus $X$ is a reconstructed recreation vehicle built and designed through collaboration using reclaimed and donated materials and a budget from contributors who believe in its cause, effectiveness, and importance. However, the physical product resulted from employing and practicing the ideals that help to define the activist architect. This project took on a second and perhaps more meaningful role in helping to develop the abilities and skill set of an activist architect because it developed in a multidisciplinary academic setting. This network of engagement has a place in architectural education and can enhance the way in which more university programs foster the development of the activist architect, an area of needed expansion and acknowledgement.

The overall execution of the project resulted in a network of stakeholders and interest groups all of which negotiated and interacted with the project manager/student of architectural activism. Since a definitive hierarchy of the roles required to realize this project does not exist, it was necessary to nimbly respond to the situation at hand. The activist architect must be present and wear the hat that needs to be worn resulting in continuous cycling - designer, PR, administrative, political, finance, business, teacher, builder, networking, community member, student, friend.

The project prompted the facilitation of collaborations between student groups in architecture, engineering, and landscape architecture through an independent study course which provided experience in participatory design, collective knowledge, and reciprocal design and dialog. Materialistically, Apparatus $X$ drew from diverse sources including salvaged materials from the theatre department, the university salvage yard, local builders, donated new products, and re-usable material from the deconstruction of the original RV unit, illustrating a necessary hyper-resourcefulness.

Ultimately, the action and facilitation required of the student project leader provided an experience in architectural activism and responsibility that poetically paralleled the roles and situations that are necessary and expected in the actual project implementation of Apparatus $\mathrm{X}$ in communities in need.

\section{NEXT STEPS FOR $X$}

The state of Apparatus $X$ lies somewhere in the intersection (or perhaps the gap) of academy and practice (Fig. 5), and crosses the bounds of the profession in a way that is needed, but challenging. With a prepared physical presence, Apparatus $X$ enables the activist architect to extend and engage communities in ways that are meaningful and sensitive, but comfortable through alternative acts of design thinking. Apparatus $X$ takes advantage of the marginalized realm of activism, and supports the ability to contribute meaningfully to complex situations of the modern world regarding housing disparity, changing building paradigms, and limited resource availability. Apparatus $X$ makes architecture accessible, engages in design activities and tasks WITH the community rather FOR the community, and creates a reciprocity/ exchange/dialog of learning, design, and action. As an architectural variable, $\mathrm{X}$ will continue to evolve as a tool of architectural activism.

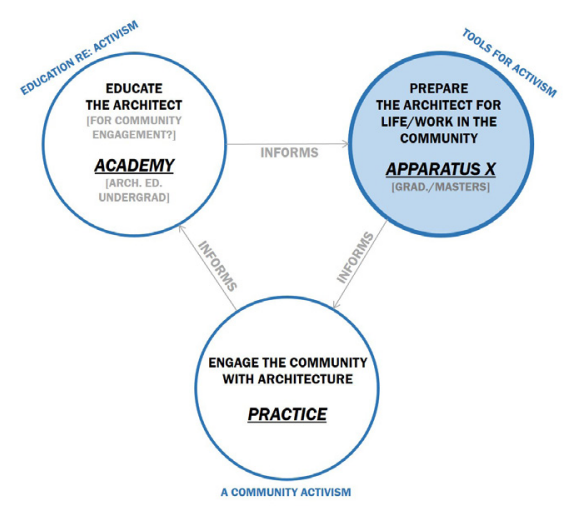

5

Figure 5: An Interesting Intersection

- or perhaps a Gap?, (Diagram: Aaron Wertman)

\section{ENDNOTES}

1. Sinha, Sumita. Architecture for Rapid Change and Scarce Resources. Abingdon, Oxon: Earthscan from Routledge, 2012. Print.

2. Bell, Bryan, and Katie Wakeford. Expanding Architecture: Design as Activism. New York: Metropolis, 2008. Print.

3. Citizen Architect Resolution. The American Institute of Architects, 2008.

4. Bell, Bryan, ed. Good Deeds, Good Design Community Service Through Architecture. New York: Princeton Architectural, 2004. Print.

5. Mi-ju, Kwon. "An Architect Available for Home Repair." SPACE MAGAZINE NO. 525 (2011). Print. 